\title{
Prospect Analysis of Hand-drawn Animation under Digital Technology
}

\author{
Shuzeng Li \\ Academy of Fine Arts \\ Northeast Normal University \\ Changchun, China \\ shuzengli1314@gmail.com
}

\author{
Bing Liu* \\ Academy of Fine Arts \\ Northeast Normal University \\ Changchun, China \\ ice8515@163.com \\ Corresponding author
}

\author{
Xuefang $\mathrm{He}$ \\ Academy of Fine Arts \\ Northeast Normal University \\ Changchun, China
}

\begin{abstract}
Interdisciplinary and cross-disciplinary integration can not only provide the viewers only give viewers a better way of behavioral experience but also bring new vitality into the industry. With the promotion of digital technology, 3D animation has developed rapidly and become the mainstream of the animation market Especially with its cool technology and real scenes; however, Disney, at one time was the king of twodimensional animation, now has closed the company in Japan, France, Canada and other countries. Disney now has to develop the 3D animation though purchasing Pixar animation.3D animation by purchasing Pixar Animation. Are hand-drawn animations going to be? The authors believe that, in the era of technology, the hand-drawn animation is not going to be eliminated, but it will be represented in another form - melting animation.
\end{abstract}

Keywords-hand-drawn animation; 3D animation; digital technology; melting animation

I. FROM TRADITIONAL HAND-DRAWN ANIMATION TO THE ERA OF DIGITAL HAND-DRAWN ANIMATION AND 3D ANIMATION

"Hand-drawn animation" is a relative concept that didn't exist before the 1990s, mainly because the animation at that time was dominated by traditional art. After the 1990s, CG technology began to be used in the animation industry, and the concept of "CG animation" was formed and distinguished from the hand-drawn animation, the traditional hand-drawn animation is called the "movement" on the paper, it is first drawn by the artist on the paper, then the camera is used to shoot the frame one by one on the paper, the post-production is finally performed. In 1915, the American animator El Hurd invented the celluloid, because of that the animated character image and the background were drawn on different celluloid films, so that these two were separated, and then the fixed camera shot the camera lens. Celluloid can change the character but the background of the picture is unchanged, the invention of the celluloid greatly reduced the number of picture frames drawn, in addition, it could increase the depth of the

The author gratefully thanks the financial support by Fundamental Research Funds for the Central Universities / Youth fund of Northeast Normal University in philosophy and social science projects - (2017QT008). field effect and improve the efficiency and expressiveness of animation; from then on, the celluloid film has been widely used in in the animation industry, it has been in production for more than half a century and this half a century is known as the "celluloid era".

The emersion of computer in the late 1980s made animations more intelligent, in 1986, the computer-made Disney Cartoon "Great mouse detective" marked the beginning of the use of digital the use of digital composition techniques in $2 \mathrm{D}$ animation scenes, and was widely used in 2D animation, as shown in Fig. 1, at the same time, the hand-drawn animation in the full sense no longer existed [1]. Computer technology is also widely used in traditional celluloid animations, compared to traditional hand-drawn animations, computer-based 2D animations can also create more textured objects and more complex movements; The Price of Egypt of Dream Works Studios has half of the lenses using computer-generated images (CGI) including several shots that separate the Red Sea [2].

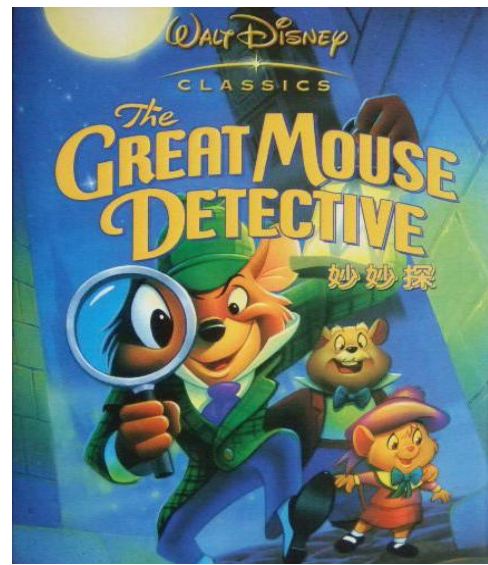

Fig. 1. The poster of Great Mouse Detective

With the development of computer technology, hand-drawn animation began to implement computer-drawn animation (paperless animation / digital hand-drawn animation). As 
computer drawing not only doubles efficiency, but also greatly reduces employees and costs, more importantly, computer technology changes the attributes and thinking patterns of traditional animation; everything can be done on computer from the previous art design, mid-term production, postsynthesis, completely paperless. Technology enables animations to be digitized, and animations begin to evolve from two-dimensions to three-dimensions. Pixar and Pacific Data Images is the pioneer of $3 \mathrm{D}$ animation in this aspect when 1978-1994 was the period of exploration of 3D animation, in 1981, John Halas produced CGI short film "The Dilemma"1995-2000 was the beginning period of 3D animation and in 1995, "Toy Story", which was directed by Pixar's John Lasseter, marked the entry of animation into the 3D era, as shown in Fig. 2. Three-dimensional technology is widely praised in the industry for its advantages of convenient modification, real space, short production cycle and strong visual effect.

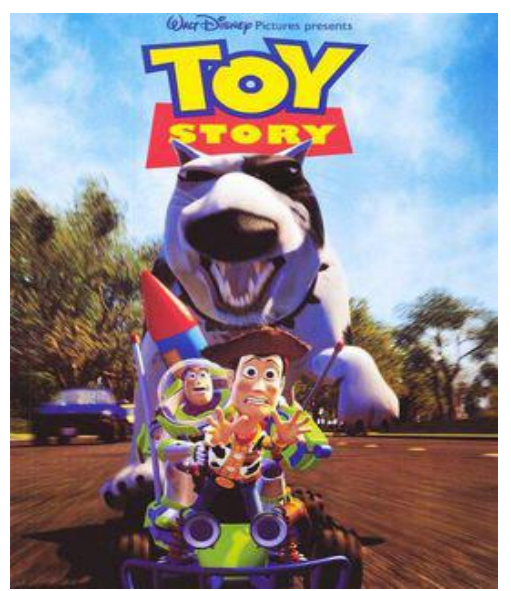

Fig. 2. The poster of Toy Story

\section{THE CURRENT DEVELOPMENT STATUS OF HAND-DRAWN ANIMATION AT DOMESTIC AND FOREIGN}

\section{A. The Development Status of Overseas Hand-drawn Animation}

The market for hand-drawn animation from the perspective of the box office: Fig. 3 is the top 20-world animation movie box office. In the list, 19 animations are 3D animations, and only one is 2D animation that is the "Lion King", released in 1994.From this list we can find out that these 19 animations are all from Disney or DreamWorks in the United States, and these companies all have turned to the $3 \mathrm{D}$ animation market in the market economy.

Fig. 4 shows the introduction of foreign animation movies in the box office rankings. Among the 20 animated films, 18 3D animations come from animation department comes from the United States, and the other two hand-drawn animations come from Japan. In the current animation market, Japanese hand-drawn animations still maintain a high box office appeal, which stems from the uniqueness of Japanese animation.

\begin{tabular}{|c|c|c|c|c|}
\hline Rank & Name & Global box office $/ 100$ million dollars & Year & Country \\
\hline 1 & Frozen & 12.765 & 2013 & U.S.A \\
\hline 2 & Minions & 11.594 & 2015 & U.S.A \\
\hline 3 & Toy Story 3 & 10.636 & 2010 & U.S.A \\
\hline 4 & Despicable Me 3 & 10.305 & 2017 & U.S.A \\
\hline 5 & Finding Dory & 10.282 & 2016 & U.S.A \\
\hline 6 & Zootopia & 10.238 & 2016 & U.S.A \\
\hline 7 & Despicable Me 2 & 9.708 & 2013 & U.S.A \\
\hline 8 & The Lion King & 9.685 & 1994 & U.S.A \\
\hline 9 & Finding Nemo & 9.367 & 2003 & U.S.A \\
\hline 10 & Shrek 2 & 9.198 & 2004 & U.S.A \\
\hline 11 & $\begin{array}{l}\text { Ice Age: Dawn of the } \\
\text { Dinosaurs }\end{array}$ & 8.867 & 2009 & U.S.A \\
\hline 12 & Ice Age: Continental Drift & 8.772 & 2012 & U.S.A \\
\hline 13 & The Secret Life of Pets & 8.755 & 2016 & U.S.A \\
\hline 14 & Inside Out & 8.574 & 2015 & U.S.A \\
\hline 15 & Coco & 8.066 & 2017 & U.S.A \\
\hline 16 & Shrek the Third & 7.990 & 2007 & U.S.A \\
\hline 17 & Shrek Forever After & 7.526 & 2010 & U.S.A \\
\hline 18 & $\begin{array}{l}\text { Madagascar3:Europe's } \\
\text { Most Wanted }\end{array}$ & 7.469 & 2012 & U.S.A \\
\hline 19 & Monsters University & 7.436 & 2013 & U.S.A \\
\hline 20 & Up & 7.313 & 2009 & U.SA \\
\hline
\end{tabular}

Fig. 3. Global Animation Movie Box Office Rankings

\begin{tabular}{|l|l|c|l|l|}
\hline Rank & \multicolumn{1}{|c|}{ Name } & Global box office/100million RMB & Year & Country \\
\hline 1 & Zootopia & 15.31 & 2016 & U.S.A \\
\hline 2 & Coco & 12.11 & 2017 & U.S.A \\
\hline 3 & Despicable Me 3 & 10.38 & 2017 & U.S.A \\
\hline 4 & Kung Fu Panda 3 & 9.98 & 2016 & U.S.A\&China \\
\hline 5 & Kung Fu Panda 2 & 6.17 & 2011 & U.S.A \\
\hline 6 & Your name. & 5.76 & 2016 & JAPAN \\
\hline 7 & STAND BY ME & 5.3 & 2015 & JAPAN \\
\hline 8 & Big Hero 6 & 5.29 & 2015 & U.S.A \\
\hline 9 & Angry Birds & 5.13 & 2016 & U.S.A \&Finland \\
\hline 10 & Ice Age: Continental Drift & 4.57 & 2012 & U.S.A \\
\hline 11 & Ice Age: Collision Course & 4.47 & 2016 & U.S.A \\
\hline 12 & Minions & 4.35 & 2015 & U.S.A \\
\hline 13 & How to Train Your Dragon 2 & 4.03 & 2014 & U.S.A \\
\hline 14 & The Croods & 3.95 & 2013 & U.S.A \\
\hline 15 & The Secret Life of Pets & 3.89 & 2016 & U.S.A \\
\hline 16 & The Incredibles 2 & 3.53 & 2018 & U.S.A \\
\hline 17 & Despicable Me 2 & 3.24 & 2014 & U.S.A \\
\hline 18 & Frozen & 2.98 & 2014 & U.S.A \\
\hline 19 & The Smurfs & 2.6 & 2011 & U.S.A \\
\hline 20 & Finding Dory & 2.5 & 2016 & U.S.A \\
\hline
\end{tabular}

Fig. 4. China introduces animation movie box office rankings

Japanese animation has the characteristics of traditional hand-drawn animation and has its own uniqueness, which mainly reflected in the overall development of Japanese animation. In this respect, it refers to the traditional production mode (such as "collective work", full-motion painting, etc.) adopted in the early stage of the development of Japanese animation in the 20th century. Miyazaki has publicly stated that he will insist on making animations in the traditional handpainted way. On the other hand, it refers to the animation concept of "making high-quality long animation" that Japan Toei Animation Co., Ltd adhered to in the 1950s.idea [3].

In the foreign movie market, we can clearly see through the fig 4 that American and Japanese animation is the main impulse for the box office though fig 4, however the United States is known for three dimensions, and Japan is known for hand-drawn animation. Outside the market, hand-drawn animation is dominated by independent animation, with colleges and independent animators as the main target. Like in the excellent art academies such as the Vancouver Film 
Academy and the Rhode Island School of Design, the teaching of hand-drawn animation is still the major course for animation students, in addition, in the world's major animation film festivals, such as the French Angkor Animation Festival, Hiroshima International Animation Festival, Ottawa International Animation Festival and other animation festivals, independent hand-drawn animation works have achieved good results. The long animation award 'Sita Sings the Blues' in the Angkor Animation Festival (USA), Ottawa International Animation Festival Best Animation Short Film Award "This Idea Is Love"(China), Oscar's best animation short film 'The Old Man and the Sea' (Russia) etc. From these excellent animation works, we can see that the independent animators still maintain the consistent exploratory and forward-looking nature, constantly explore and break through the creative methods and techniques.

\section{B. The Development Status of Domestic Hand-drawn Animation}

The digital age of the $21^{\text {st }}$ century has made the digital animation gradually occupy the commercial market; meanwhile the hand-drawn animation has been also disappearing. Although the Chinese animation industry has increased in recent years, compared to the international influence of the "Chinese School" in the 1950s and 1960s, it still remains huge space to improve.

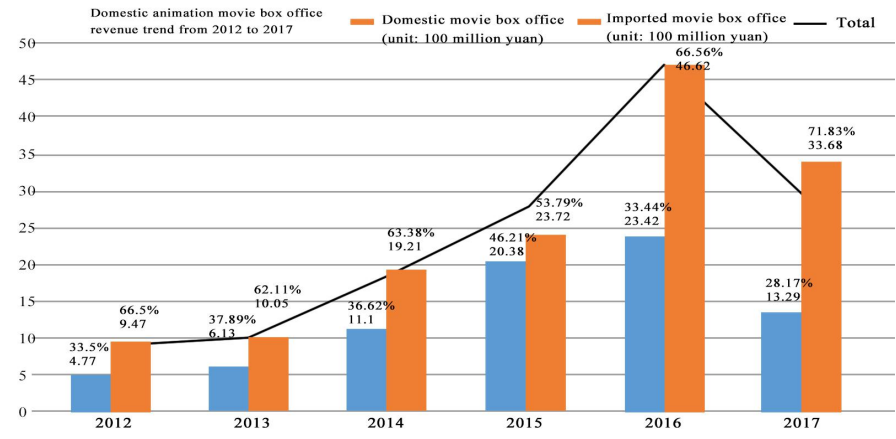

Fig. 5. Office data of Domestic animation films and imported animation movies counted [4].

Fig. 5 is the box office data of Chinese animation films and imported animation movies counted by Shuyu dream factories. We can figure out that the total number of boxed animation films was 4.17 billion yuan in 2017; it decreased by 2.287 billion yuan compared to 2016 , with a decrease of $32.7 \%$ yearon-year. Among them, the total number of domestic animation movie box office was 1.329 billion yuan, accounting for only $28 \%$ of the total box office, while the total number of imported animation movie box office was 3.388 billion yuan, accounting for $72 \%$. In addition, the nine domestic animation films released in 2017 are the re-enactment of the animated film versions of previous years. The number of new films has shrunk severely, and the box office has also decreased by 1.013 billion compared with 2016, most of the 39 animated films released are still low-profile animation movies [5].

Schools is central group for "animation school" and experimental animation creators, and many animators have written articles to explore the future trends of Chinese hand- drawn animation, for example, "An Introduction to Animation" edited by Sun Lijun, a professor at the Beijing Film Academy Animation School, "Animation China" published by Shanghai Fine Arts Film Studio, and Zhang Xiaoye's "Animation Short Film Creation". In the domestic college animation course setting is generally set to two-dimensional animation direction and three-dimensional animation direction, and hand-painted animation as an important course to cultivate students' skills and professional ability; in this context, there are many highquality hand-painted experimental animations, such as the "low-headed family" of the Central Academy of Fine Arts, "Yinghe" and "Shang" of the Chinese Academy of Fine Arts, "Elevator" and "My Grandpa" of the Communication University of China.

In addition, the Chinese government has also increased its support for animation in recent years; hand-drawn animation has also been praised by many independent creators. In 2016 , the box office of "Big Fish \& Begonia" reached 74.6 million yuan on its debut day, breaking the record of the first-day box office of Chinese domestic animation. The success of "Big Fish \& Begonia box" made many animators and fans excited, the American Animation Insider Anime Review " Big Fish \& Begonia box" is an impressive animated film, the work is full of Chinese mystery and romance, and is comparable to the best animated films in Asia [6].

Independent animations created by Chinese independent animators such as Liu Jian, Lei Lei, Ye Ding and Deng Weifeng also inject new vitality into Chinese hand-drawn animation. Independent animation is an art with contemporary characteristics, animated art that is not interfered by business and ideology and has an independent spirit. Liu Jian's animated feature film "Stinging I" was shortlisted at the 2010 Angxi International Animation Film Festival in France. The French "Movie Handbook" is titled "China's New Breakthrough" and highly praises "Stinging $\mathrm{Me}^{\text {": }}$ "The real surprise in the competition unit comes from China, his first narrative film "Stinging Me" marks Chinese animation, the movie is alive and beautiful." [7]

\section{THE APPLICATION OF DIGITAL TECHNOLOGY IN HAND- DRAWN ANIMATION}

\section{A. Technology Integration}

British illustrator Lzzy Burton, as shown in Fig. 6, produced the short film "Via". The short film tells us a journey of life through beautiful environment and vivid characters, it tells us that every day when we open our eyes, we should take a good look at the beautiful things happening around us, share the experiences with the people we love, and even have a glimmer of hope and learn from them in the lowest valley of life. First time when I watch the short film, it makes me feel that it is a well-made 2D animation, actually, the character sin this animation is banded and animated in Maya, the background is drawn by Photoshop and then introduced into $\mathrm{AE}$ and synthesized with the environment.

Blender is Kaiyuan cross-platform all-round 3D animation software, from modeling, materials, animation, rendering to post-audio and video editing, it's a fully integrated authoring 
suite. In Blender, you can freely add custom tools such as Python scripts to implement the modeling process, in addition, Blender has the function of engraving and brush software to meet the creative needs of artists, at the same time, the UV image can be exported using some software such as Photoshop. In 2018, Blender issue the promotional animation "HERO" by director Daniel Martinez Lara. In "HERO", he created a vivid 2D animation in 3D space, which uses Blender 2D animation with 3D layers and lights, as shown in Fig. 7.

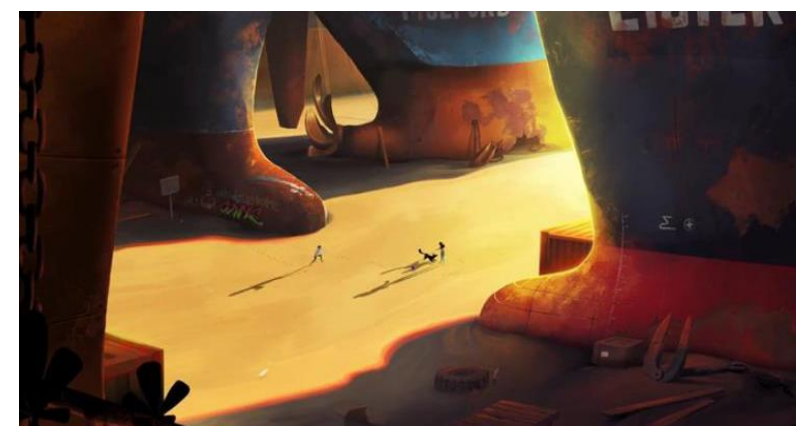

Fig. 6. The poster of VIA

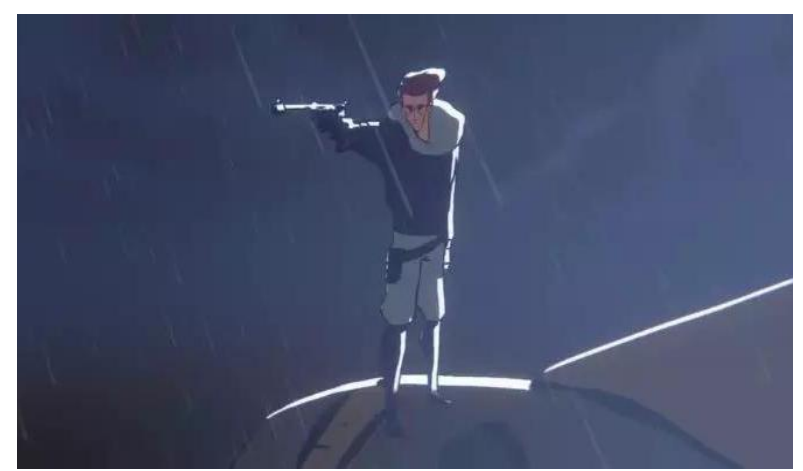

Fig. 7. The poster of HERO

The Grease Pencil in Blender has a variety of brushes, enabling 2D frame-by-frame rendering in 3D layers, when coloring, you can color and adjust the position of the patch area frame by frame, and adjust the light to change the ambient light; furthermore, you can create your own animation library, draw the key frame, the middle frame and then complete the action by editing, morphing and dragging the character, compared with hand-painting one by one, you can save a lot of time and manpower. The comprehensive application of various software makes our faster and easier to complete animations, while also reducing the cost of investment.

\section{B. Form Combination}

The combination of digital technology and two-dimensional animation can increase the depth of the picture with the depth of field, make the animation more realistic. Through the scenes in the software to create auxiliary lines, it is convenient to construct the perspective relationship of the screen perspective to achieve a sense of space. In addition, it is also possible to realize scene and character exchange, setting a camera in the software; you can switch the changes at any time and realize the change of depth of field.
If you use 2D hand-drawn, it takes much time and effort. The combination of digital technology and 2D animation cuts down animation production costs and time and improves designer productivity. Like a hand-painted striped plaid character, if it is difficult to achieve with hand-drawn, so the animator will avoid this phenomenon in hand-drawn animation, if you use digital technology, you need to model and then adjust the bone to realize the character running, and the clothes change naturally as well.

The combination of digital technology and 2D animation can easily achieve rendering effects. In 2D animation scenes, scenes and characters are not easy to express the layering of the picture, but in digital technology, software can create a strong sense of atmosphere and enhance the realism of the scene.

\section{CONCLUSION}

Technology can never replace art, but it can make art represented in many forms, so for hand-drawn animation, to a certain extent, hand-drawn animation can promote the uniqueness and artistry of new media animation [8]. Twodimensional hand-drawn animation couldn't survive in the commercial market nowadays, if only it would rely upon the persistence and emotions, touching story scripts and taking advantage of their unique strengths are long-lasting methods, combine this advantage with current digital technology, it can release new vitality in innovation and progress. In addition, under the current digital technology, it is difficult for a single agent to keep development, therefore, hand-drawn animations must be complemented by three-dimensional animations, must take advantage of 3D animations, and continuously explore the possibility of the unknown of hand-drawn animations, bringing more possibilities for hand-drawn animation. Finally, the future of hand-drawn animation is not only presented in a technical form, but in a new presentation of a variety of technologies melting animation.

\section{REFERENCES}

[1] Lihong. "Two-dimensional hand-drawn animation in China's new development direction," Design art and theory, 2017, pp.92. (In Chinese)

[2] David Podwell. "Christine Thompson, Fanbei Traslation, World Film History," Peking University Press, 2016, pp.924.

[3] Wang Lixuan. "Obstacle under rationality-Hayao Miyazaki insists on the traditional hand-painted animation," Cultural and artistic studies, 2015, pp.133. (In Chinese)

[4] http://www.sohu.com/a/212773926_115832 (In Chinese)

[5] Liu Fangzheng. "2017 China Film Market Review," China Film Marke, pp.17-18.2018. (In Chinese)

[6] Zhangjin, Guo Xuewen. "Narrative Analysis of the Animated Film "The Big Fish Begonia", Film literature, pp.103. 2018. (In Chinese)

[7] Gujuan. "Talking about the Commercialization Tendency in Chinese Independent Animation Creation," Nanjing University of the Arts paper.2016. (In Chinese)

[8] Sunjing. "Inheritance and Continuation-Traditional hand-drawn animation in the digital age," Hubei Academy of Fine Arts paper, 2015. (In Chinese) 